\title{
FORMAÇÃO DIDÁTICO-PEDAGÓGICA EM SAÚDE: HABILIDADES COGNITIVAS DESENVOLVIDAS PELOS PÓS-GRADUANDOS NO AMBIENTE VIRTUAL DE APRENDIZAGEM
}

\author{
Didactic and pedagogic training in health care: \\ cognitive skills developed by postgraduate students \\ in a virtual learning environment
}

\author{
Lidia Ruiz-Moreno $^{1}$. Maria Teresa Meirelles Leite ${ }^{2}$ • \\ Claudia Ajzen ${ }^{3}$
}

\begin{abstract}
Resumo: O fórum de discussão do ambiente virtual Moodle foi adotado na disciplina Formação Didático-Pedagógica em Saúde, oferecida pelo Cedess da Unifesp. O objetivo deste trabalho foi identificar as habilidades cognitivas e sociais desenvolvidas e as unidades temáticas privilegiadas pelos pós-graduandos. As mensagens foram classificadas segundo as habilidades de: a) propor, concordar, indagar; b) problematizar, discordar, questionar; e c) generalizar, esclarecer, sintetizar, estender. Os alunos desenvolveram habilidades nas três categorias consideradas e a análise de conteúdo das mensagens foi realizada em relação a cada categoria. Os temas abordados evidenciaram a integração de conhecimentos nos níveis pessoal, institucional, social e político. Os alunos construíram conhecimentos numa dimensão coletiva, onde as interações interpessoais e com os conteúdos, mediadas pelas TIC, tiveram importante papel na aprendizagem. Estas interações potencializaram a aprendizagem entendida como processo social, de modo que a análise do processo deslocou-se do indivíduo isolado para as relações dos sujeitos e seus papéis na sociedade.
\end{abstract}

Palavras-chave: Formação de professores. Tecnologia educacional. Fórum de discussão. Docência. Ambiente virtual de aprendizagem.

\begin{abstract}
At the graduation course on Teaching in Health, offered by Cedess/Unifesp, an online discussion forum was set up. The aim of this study was to identify the cognitive and social skills developed and the thematic units preferred by postgraduate students. The messages were classified according to the cognitive abilities. Content analysis of messages was performed for each category. Students developed cognitive and social skills in the three categories. The discussed topics showed the integration of knowledge at personal, institutional, social and political levels. Students built knowledge in a collective dimension, where the interpersonal interactions and content, mediated by ICTs, have played an important role in learning. These interactions have strengthened learning, understood as a social process, so that the analysis has shifted from the isolated individual into conceiving the relationship among subjects and their roles in society.
\end{abstract}

Keywords: Teacher training. Educational technology. Discussion forum. Virtual learning environment. Education.

\footnotetext{
${ }^{1}$ Centro de Desenvolvimento do Ensino Superior em Saúde (Cedess), Universidade Federal de São Paulo (Unifesp). Avenida Dr. Altino Arantes, 620, apto. 81. São Paulo, SP, Brasil. 00.042-003. lidia.ruiz@unifesp.br

${ }^{2}$ Departamento de Informática em Saúde (DIS), Unifesp. São Paulo, SP, Brasil.

${ }^{3}$ Programa de Pós-Graduação em Ensino em Ciências da Saúde, Unifesp. São Paulo, SP, Brasil.
} 


\section{Ensino superior e novas tecnologias de informação e comunicação}

O uso de Tecnologias de informação e comunicação (TIC) na educação demanda refletir sobre decisões assumidas pelas Instituições de Ensino Superior (IES) sobre a formação docente para promover a educação de cidadãos críticos e comprometidos com a solução de problemas da maioria da população.

Embora existam experiências bem-sucedidas de educação a distância $(\mathrm{EaD})$ no Brasil, a formação de profissionais da saúde mediada por TICs, oferecida por IES, é limitada. A formação de professores nas licenciaturas e disciplinas de pós-graduação ainda não parece haver incorporado um preparo técnico-pedagógico para as possibilidades dos ambientes virtuais de aprendizagem. Utilizar estes espaços para a organização do trabalho pedagógico requer reformular esse processo de formação.

No modelo pedagógico vigente na maioria das escolas, o aluno é visto como um receptor de conteúdos cuja tarefa é assimilar e reproduzir, ao invés de problematizar, analisar, refletir, discutir e conversar. Moreira, Costa e Oliveira (2001) situam três principais concepções do processo de ensino-aprendizagem que determinam a prática pedagógica com uso da tecnologia educacional. $\mathrm{Na}$ concepção empirista, o aluno é considerado um ser passivo no qual são depositadas informações. Neste modelo, o uso de tecnologias consiste em disponibilizar conteúdos no ambiente tecnológico e, ao finalizar o processo, realizar avaliações para testar os conteúdos adquiridos. Já, na concepção racionalista, a aprendizagem é um processo autônomo regulado pelo amadurecimento orgânico das estruturas racionais. As atividades são centradas no aluno, que depende exclusivamente do seu potencial cognitivo para realizar a aprendizagem, sendo secundarizada a mediação docente neste processo.

As dicotomias das concepções empirista e racionalista são superadas pela teoria sociointeracionista de Vygotsky (1995), que enfatiza que a construção de conhecimentos ocorre no processo de interação com outros indivíduos, mediados ou não por recursos tecnológicos. Esta abordagem pedagógica difere das anteriores por colocar, no centro do processo ensinoaprendizagem, os contextos político, econômico, social e cultural onde ocorre a ação educativa. Nessa concepção, o ser humano não pode ser compreendido fora de seu contexto, ele é o sujeito de sua própria formação, e se desenvolve por meio da contínua reflexão sobre seu lugar no mundo, sobre sua realidade. Essa conscientização é pré-requisito para o processo de construção individual de conhecimento ao longo de toda a vida, na relação pensamento-prática. Visa a consciência crítica, que é a transcendência do nível de assimilação dos dados do mundo concreto e imediato, para o nível de percepção subjetiva da realidade, como um processo de relações complexas e flexíveis ao longo da história (MIZUKAMI, 1986).

Uma das possibilidades para estabelecer transformações no sistema educacional, visando a formação da consciência crítica, consiste em desenvolver processos de comunicação, que envolvam as dimensões cognitivas, afetivas, sociais e éticas, entre alunos e professores abertos, democráticos e interativos (MORAN, 2003). Valorizam-se, cada vez mais, a interação e a troca de informações entre os atores envolvidos no processo educativo e o estímulo à criatividade em substituição à reprodução passiva de conhecimentos já existentes.

$\mathrm{O}$ uso de tecnologias que facilitam o acesso e troca de informações, ampliando a possibilidade de escolha de alunos e docentes, pode constituir um facilitador do processo educativo. Em relação ao acesso da população à informação, Vygotsky (1995) define a tecno- 
logia como um dos mediadores culturais, criados pelo homem, que possibilita sua relação com o mundo material.

Embora o autor tenha vivido num tempo no qual não existiam computadores e internet, seu referencial histórico, social e cultural permite, hoje, dialogar, a partir de sua teoria, com esses novos instrumentos culturais. Para o autor, a relação do sujeito com o conhecimento não é uma relação direta, mas mediada. Esta mediação se realiza via instrumentos e signos. No trabalho, o homem utiliza instrumentos para efetuar modificações na realidade. Ao fazê-lo, modifica a si mesmo, numa relação dialética. Assim, o uso de instrumentos é também uma forma de humanização, pela qual o homem transforma o curso de sua existência de natural para cultural.

Na visão de Freitas (2009), Vygotsky constrói, a partir da ideia de instrumento material técnico (o meio pelo qual a atividade humana externa é dirigida para o controle da natureza), o conceito de signo (meio de atividade interna dirigido para o controle do próprio individuo). Assim, segundo a autora, é possível afirmar que, para Vygotsky, existem três tipos de mediadores: ferramentas materiais, ferramentas psicológicas e outros seres humanos.

Pino (2005) afirma que instrumentos materiais e símbolos constituem os dois meios de produção de cultura, que têm em comum o fato de serem mediadores da ação humana sobre a natureza e sobre as pessoas, respectivamente. Na visão de Freitas (2009), o computador e a internet, como objetos criados pelo homem, são produções culturais que se caracterizam por serem constituídas por dois componentes: um material e outro simbólico. O hardware representa a parte física, e o software, a dimensão simbólica. Neste sentido é possível compreender o papel mediador exercido por estes instrumentos que são, ao mesmo tempo, tecnológicos e simbólicos, e que potencializam novas formas de pensamento.

A hipermídia (GOSCIOLA, 2003), caracterizada pela possibilidade de utilizar vários canais sensoriais, combinando textos, imagem cor, som e movimento, cria uma nova modalidade comunicacional, possibilitada pelo meio digital: a interatividade que envolve a intervenção do interlocutor de forma síncrona ou assíncrona. Já que ele não é um mero receptor e pode interferir, modificar, reinventar. Estas novas tecnologias criam desafios para as instituições de ensino, acostumadas ao ensino tradicional, já que possibilitam novas formas de comunicação centradas nas interações discursivas professor-aluno e na aprendizagem colaborativa, nas quais o papel mediador do professor é fundamental.

No livro 'Formação social da mente', Vygotsky (1998) afirma que o processo de construção do conhecimento acontece primeiro no plano interpessoal para, depois, acontecer no plano intrapessoal - a aprendizagem ocorre quando a pessoa internaliza o que já foi vivenciado externamente em forma coletiva. A relação do sujeito com o conhecimento é viabilizada pela linguagem, de modo que o conhecimento se constrói nas relações interpessoais. Alunos e professores participam de uma construção compartilhada de conhecimentos. O professor atua no processo de aprendizagem, apresentando, problematizando, demonstrando, orientando, provocando reflexões, críticas e promovendo ações transformadoras sobre a realidade.

Os ambientes de comunicação mediados por computadores com acesso à internet propiciam o desenvolvimento de interações educativas mais amplas, impensáveis no passado recente, sendo possível combinar momentos presenciais e a distância, onde os participantes podem trocar ideias e experiências, vivenciar atividades individuais e grupais e criar condições para a construção de conhecimentos de forma colaborativa (KENSKI, 2001). 
Segundo Blikstein e Zuffo (2003), é urgente a formação de educadores que lidem com as novas tecnologias de forma crítica e reflexiva, para superar resistências e preconceitos ou, ainda, evitar a ilusão de que esses novos instrumentos de per si poderiam ser a solução para todos os problemas educacionais da atualidade.

Os alunos, por sua vez, precisam desenvolver competências como a busca ativa de informação e senso crítico, além de uma participação responsável no processo de aprendizagem e avaliação. Eles apresentam, geralmente, maior familiaridade com essas ferramentas, mas é preciso que também desenvolvam habilidades cognitivas e sociais.

Um argumento usado contra a EaD é a dificuldade de se avaliar o aluno. De modo geral, o professor parte do pressuposto de que avaliar a aprendizagem consiste em quantificar a informação transmitida pelo docente e assimilada pelo aluno (FREITAS; SEIFERT, 2007). Neste sentido, a EaD pode contribuir para superar o paradigma da pedagogia tradicional, demandando que o professor valorize outros aspectos, além da dimensão individual, como a construção colaborativa do conhecimento com o professor/tutor atuando como mediador. Nesta abordagem, o professor prioriza a avaliação qualitativa das interações ocorridas numa perspectiva formativa.

No momento em que as instituições de Ensino Superior ampliam propostas educativas de caráter semipresencial, com a utilização de tecnologias digitais, amparadas em portaria do Ministério de Educação (BRASIL, 2004) que permite que os cursos de Ensino Superior ofereçam até $20 \%$ da carga horária a distância, consideramos relevante compartilhar experiências que utilizem ambientes virtuais, como forma de complementar os encontros presenciais. É importante empreender investigações no contexto particular dos meios eletrônicos de interação como suporte à educação, com a finalidade de afinar uma metodologia coerente com o modelo pedagógico orientado ao desenvolvimento do pensamento crítico dos estudantes, e que valorize o papel motivador, condutor e mediador do docente numa comunidade virtual de aprendizagem (FËDEROV, 2006).

O ambiente virtual Moodle, idealizado segundo princípios socioconstrutivistas é uma plataforma de uso livre, onde os professores podem conduzir cursos via internet por meio de sua instituição. No Moodle, é possível disponibilizar arquivos de texto, áudio e vídeo, e contar com recursos de comunicação síncrona, como chats, e assíncrona, como fóruns de discussão, wikis (textos colaborativos) e blogs. Em relação à avaliação da aprendizagem, o ambiente permite abordagens quantitativas e qualitativas. É possível elaborar escalas de avaliação personalizadas para cada atividade, permitindo a avaliação contínua e formativa.

Na Universidade Federal de São Paulo (Unifesp), o Moodle é administrado pelo Departamento de Informática em Saúde (DIS) ${ }^{4}$ desde 2005, como recurso de apoio ao ensino presencial e, também, como plataforma de suporte para cursos online na graduação e pósgraduação (LEITE, 2007).

\footnotetext{
${ }^{4}$ Contamos com a colaboração de Antônio Aleixo da Silva, do Departamento de Informática em Saúde (DIS) da Unifesp, que atuou como Designer Instrucional, responsável por planejar e estruturar a página no Moodle, coordenar o módulo de aproximação a este ambiente virtual e oferecer suporte técnico durante o desenvolvimento da disciplina.
} 
Formação didático-pedagógica em saúde: ...

A Formação Didático-Pedagógica em Saúde é oferecida desde 1996, na modalidade presencial, pelo Centro de desenvolvimento do Ensino Superior em Saúde (Cedess), como disciplina obrigatória para os pós-graduandos da instituição. Na visão de Batista et al. (2004), a formação docente não significa apenas a instrumentação técnica, mas, fundamentalmente, uma reflexão crítica das concepções e práticas, considerando a realidade sócio-histórica onde estas se concretizam. No contexto de uma parceria com o Departamento de Informática em saúde da Unifesp, foi elaborada, em 2007, uma proposta bimodal da disciplina com 20\% da carga horária desenvolvida no ambiente virtual de aprendizagem Moodle.

\section{Objetivos}

No marco da disciplina de Formação Didático-Pedagógica, proposta bimodal, o objetivo deste trabalho foi: identificar as habilidades cognitivas e sociais desenvolvidas, analisar o conteúdo das mensagens postadas pelos pós-graduandos num fórum de discussão num ambiente virtual de aprendizagem, e analisar a experiência educativa na perspectiva dos alunos.

\section{Delineamento metodológico}

Participaram da pesquisa noventa pós-graduandos da Unifesp, integrantes de três turmas oferecidas entre 2007 e de 2008. Suas profissões de origem abrangiam: Medicina, Enfermagem, Biologia, Biomedicina, Fonoaudiologia, Educação Física, Fisioterapia, Odontologia e Nutrição.

O plano de ensino da disciplina incluía a participação num fórum de discussão sobre o papel das TICs na educação. O texto 'Desafios para a era do conhecimento' (GADOTTI, 2006) serviu como referência para iniciar o debate no fórum virtual.

A coleta de dados foi realizada a partir dos registros disponíveis no Moodle sobre participação, frequência das mensagens disponibilizadas pelos pós-graduandos, e de questionário de avaliação da disciplina, aplicado ao final da experiência. Numa primeira etapa, foram identificadas as habilidades cognitivas e sociais presentes nas mensagens (VAN DER LINDEN; PICONEZ; ANDRE, 2007) e, posteriormente, realizada análise temática das mensagens classificadas dentro de cada categoria (MINAYO, 2004). Esta análise temática buscou identificar, nas mensagens, as unidades de contexto, passo fundamental para situar o pano de fundo do texto das mensagens a ser decodificado, ancorando, posteriormente, a compreensão e significado das unidades de registro. Agrupando as unidades de registro a partir da confluência de seus significados, foi possível elencar, nas unidades temáticas, os núcleos de sentido que compõem uma comunicação (FRANCO, 2007).

\section{Resultados}

Dos noventa alunos participantes, 83 acessaram a bibliografia recomendada e 79 participaram do fórum de discussão. As 183 mensagens foram classificadas, segundo o tipo de 
habilidades cognitivas predominantes, em: a) propor/concordar/indagar (54 mensagens); b) problematizar/discordar/questionar (57 mensagens); e c) generalizar/ esclarecer/sintetizar / estender (72 mensagens). Segundo Van Der Linden, Piconez e Andre (2007), estas habilidades abrangem dimensões cognitivas e sociais da aprendizagem, e contribuem para a construção do conhecimento e aprendizagem cooperativa.

Num segundo momento, a análise de conteúdo das mensagens classificadas em cada tipo de habilidade permitiu identificar: as unidades de contexto, unidades de registro e unidades temáticas. Na categoria a) propor/concordar/indagar, foi possível identificar 60 unidades de contexto, 77 unidades de registro e três unidades temáticas, a seguir: 1) o impacto das TICs na sociedade e na educação, 2) o papel do professor e das instituições educativas no uso de TICs, e 3) a democratização do acesso às TICs.

Estas unidades de contexto e de registro extraídas das mensagens apontam para a existência de conhecimentos prévios, que constituíram o ponto de partida para as discussões marcadas por atos cognitivos que provocaram novas indagações.

A seguir, exemplos de unidades de contexto e unidades de registro (em negrito), extraídas das mensagens dos alunos no fórum de discussão, classificadas na categoria a) propor/ concordar/indagar:

Como inserir as TICs na sociedade? Como podemos trabalhar com essas perspectivas? Penso que antes de servir de bússola, precisamos entender, compreender o cenário atual, suas realidades e necessidades.

Um ponto que me chama atenção no texto é o papel do professor que deverá estar preparado para ser não apenas um mensageiro de informações e sim aquele que deverá fornecer estratégias para construção do conhecimento a partir das informações que cada aluno julgar necessário para seu crescimento.

Para o autor do texto discutido a função da escola será, cada vez mais, a de ensinar a pensar criticamente. Para isso é preciso dominar mais metodologias e linguagens, inclusive, a linguagem eletrônica.

$\mathrm{Na}$ educação, as transformações tecnológicas, com políticas públicas adequadas, permitiram uma maior democratização da informação e do conhecimento e a educação deixará de ser apenas transmissão cultural para intervir na transformação social.

$\mathrm{Na}$ categoria b) discordar/problematizar/questionar, foram identificadas, nas mensagens do fórum, 66 unidades de contexto, 72 unidades de registro e três unidades temáticas referidas a: 1) O uso de TICs nas precárias condições de trabalho dos professores, 2) as contradições na formação de cidadãos críticos no capitalismo, e 3) os entraves para a democratização da educação, considerando as desigualdades no Brasil.

A análise das mensagens classificadas nesta categoria denotou um comportamento crítico e indicou a possibilidade de o aluno discordar do ponto de vista dos colegas, do professor e dos autores indicados. Neste sentido, representam um avanço em relação ao ensino tradicional, no qual o professor é detentor do saber instituído e o aluno assume postura passiva (ALMEIDA FILHO, 2007). 
A seguir, exemplos de unidades de contexto e unidades de registro (em negrito), extraídas das mensagens dos alunos no fórum de discussão, classificadas na categoria b) discordar/problematizar/questionar:

Sem uma escola capaz de oferecer uma formação básica decente, o país não conseguirá no futuro repor sua capacidade de geração de conhecimento. Esse problema tem de ser solucionado antes de se pensar em formas eficientes de usar os meios audiovisuais e a internet.

Então, como formar um cidadão solidário, contestador, com conhecimentos generalizados se a própria sociedade exige e acaba por formar um indivíduo mais individualista? Surgem então alguns questionamentos. Como balancear e inserir essas novas tendências dentro da sociedade?

Outro ponto é que a informação está sendo popularizada, mas o conhecimento ainda é elitizado. Este fato torna os paises em desenvolvimento, como o Brasil extremamente subjugados em relação aos desenvolvidos.

$\mathrm{Na}$ categoria c) generalizar/esclarecer/sintetizar/estender, foram identificadas 81 unidades de contexto e 92 unidades de registro que permitiram inferir quatro unidades temáticas: 1) valorização do trabalho do professor e uso reflexivo das TICs para superar o modelo transmissivo de ensino, 2) implementação de projetos educativos interdisciplinares, 3) necessidade de integrar aspectos econômicos, sociais, éticos e ecológicos nos processos de inclusão social, e 4) compromisso pessoal dos pós-graduandos no papel de professores e pesquisadores nos processos de transformação social.

Esses termos sinalizaram posicionamentos marcados pela discussão em maior nível de aprofundamento. As ideias foram rediscutidas, através do processo de interação, de compartilhamento na construção do conhecimento e elaboração de propostas de mudança.

A seguir, exemplos de unidades de contexto e unidades de registro (em negrito), extraídas das mensagens dos alunos no fórum de discussão, classificadas na categoria c) generalizar/esclarecer/sintetizar/estender:

Valorizar todos os atributos do professor, utilizar todos os meios disponíveis e colocá-los ao maior número de pessoas possíveis, nos dará sim uma perspectiva melhor para o futuro.

Acredito que para se ter uma educação de qualidade é necessário restaurar os princípios éticos e morais, do indivíduo, sem perder de vista os aspectos sócio-econômicos que regem a sociedade.

É claro que uma nova forma de educação, pautada principalmente em novas tecnologias, impõe muitas barreiras a uma grande massa 
desfavorecida, mas é exatamente nesse ponto que a política, a economia e a educação têm que andar juntas, para elaborar estratégias que permitam que os novos recursos beneficiem a todos.

É nosso dever como pesquisadores e professores ter essa consciência para estarmos preparados para ajudar nessa transformação coletiva pela qual todos precisamos passar. É um grande desafio.

\section{Discussão}

O fórum sobre o uso de TICs na educação permitiu desenvolver habilidades cognitivas e sociais relacionadas à recuperação dos conhecimentos prévios, autorreflexão, problematização do saber, contextualizando e integrando os conhecimentos nos níveis pessoal, institucional, social e político (RUIZ-MORENO; PITAMIGLIO; FURUSATO, 2008). O compromisso com as ações transformadoras, por parte dos pós-graduandos, denotou a ampliação da consciência cidadã dos participantes.

Segundo Vygotsky (1998), as interações pessoais possibilitam mudanças cognitivas com a consequente reelaboração das ideias. No processo social, as ideias são elucidadas resultando em novas concepções, em avanços em termos de proposições, sínteses, teorias, hipóteses, aplicáveis em contextos diversos. Na interação de uma comunidade de aprendizagem, há um incentivo à troca de saberes, processa-se o esclarecimento dos pontos de vista e a convergência intelectual (HARASIM; TELES; TUROFF, 2005). Através da comunicação, busca-se: a produção de significados, conquista da autonomia, compreensão e ação crítica, além da possibilidade de construção de conhecimentos de ordem cognitiva, afetiva e de ação (KENSKI, 2001).

Visschers-Pleijers et al. (2004) entendem que a interação tem alto peso para predizer o sucesso de um grupo. Segundo esses autores, a qualidade da interação é essencial para o sucesso da discussão em grupo, visto que os estudantes testam hipóteses, compartilham e constroem conhecimento para sintetizar a informação adquirida em seu estudo individual, e aprendem uns com os outros.

Dolmans et al. (2005, p. 732) declaram que "aprendizagem é um processo de criação de significados e construção de interpretações pessoais do mundo baseada nas experiências pessoais e interações". Segundo os autores, na aprendizagem colaborativa, os estudantes, ao partilharem informações, "elaboram, verbalizam, co-constroem, se apoiam, se criticam e se sintonizam social e cognitivamente" (DOLMANS et al., 2005, p. 39).

A análise das mensagens no fórum de discussão no ambiente virtual de aprendizagem revelou que os alunos processaram e problematizaram informações em forma de reflexões e de conhecimentos construídos a partir da dimensão coletiva de aprendizagem. Este processo, no qual foram respeitadas as diferentes óticas dos participantes, leva ao entendimento de que as interações interpessoais e com os conteúdos, mediadas por TICs, tiveram um importante papel na aprendizagem.

No processo vivenciado, os participantes ressignificaram o uso da tecnologia como um meio através do qual os indivíduos constroem relações e conexões entre suas experiências 
e os fenômenos concretos do mundo (OLIVEIRA, 1993). Neste sentido, a internet, tomada em si mesma como núcleo de sustentação do processo, não garante a construção de conhecimentos. É preciso uma prática pedagógica bem estruturada, que favoreça as interações e considere o contexto social e cultural para alcançar os resultados esperados, segundo constatamos nesta experiência educativa.

Hmelo-Silver (2004) define que, para ser um bom colaborador, é preciso desenvolver habilidades sociais, e acrescenta que, a partir de uma perspectiva sociocultural, o conhecimento é construído através de interações sociais. Holen (2000) descreve que a interação nos espaços grupais fornece um contexto para desenvolver objetivos educacionais, dentre eles trabalhar em grupo, ou seja, desenvolver "habilidades sociais" (HOLEN, 2000, p. 485), o que adiantará as relações profissionais de cada um com os pacientes e colegas de trabalho.

A colaboração é necessária em todos os ambientes que lidam com a saúde, nesse sentido os estudantes devem aprender a colaborar efetivamente. Qualquer curso da área da saúde que prima pela formação adequada de profissionais deve preconizar, no método adotado, atividades que desenvolvam, nos estudantes, competências que os ajudarão a lidar com as necessidades da população. Dentre estas, destacam-se as habilidades de cooperar e atuar em equipe multiprofissional, previstas nas Novas Diretrizes Curriculares Nacionais para os cursos da área da Saúde (BRASIL, 2001).

\section{Avaliação da experiência educativa: a perspectiva dos pós-graduandos}

Com o objetivo de conhecer a opinião dos pós-graduandos sobre a experiência vivenciada, foi aplicado um questionário. Os núcleos que orientaram a análise dos dados compreenderam: experiência prévia, facilidades, dificuldades e sugestões em atividades educativas no espaço virtual.

Os resultados evidenciaram que $81 \%$ dos participantes não tinham experiência prévia com o Moodle. Porém os alunos perceberam positivamente a experiência e consideraram o Moodle um ambiente amigável, que favorece o aprendizado colaborativo, ressaltando: a possibilidade de acesso a diferentes materiais didáticos, a edição contínua e a revisão das mensagens postadas, a flexibilidade espacial e temporal, a facilidade de trocar informações; somadas à possibilidade de interagir com pessoas de diferentes profissões num clima de respeito mútuo.

Entre as dificuldades, relataram problemas iniciais de acesso à internet, falta de tempo e ausência de contato presencial. A maioria dos alunos sugeriu ampliar o uso do Moodle na disciplina com: agendamento das atividades, inclusão de comunicados, textos e audiovisuais, incentivo para os alunos abrirem seus próprios fóruns de discussão e realização de discussões síncronas.

Os alunos apontaram também para a necessidade de se combinarem encontros virtuais e presenciais. Existem pesquisas indicando que o relacionamento humano pode ser enriquecido no meio virtual, onde o aluno pode ser mais ativo e autônomo na busca e ressignificação do conhecimento (MAIA; MATTAR, 2007; PALLOF; PRATT, 2002).

Sobre a possibilidade de utilizar o espaço virtual no papel de professores, os pósgraduandos se mostraram motivados a utilizar o ambiente de forma similar à adotada pela disciplina, com disponibilização de conteúdos e discussões em fóruns que permitam desenvolver competências técnicas e sociais. 
No atual contexto de expansão da EaD no Brasil, espera-se que, a médio prazo, aumente a quantidade de alunos com experiência prévia em atividades educativas a distância. Os estudos sobre possibilidades e limites da formação de professores críticos e reflexivos revelam que é importante considerar que os docentes contemporâneos foram educados num ambiente pré-cibernético, enquanto as gerações mais jovens têm maior familiaridade com as novas tecnologias, criando novas demandas aos educadores.

\section{Considerações finais}

A utilização das TIC na educação precisa estar acompanhada de estudos sobre seus efeitos nas relações sociais, na produção de saberes, na construção de identidade, no processo de ensino-aprendizagem e na avaliação. No presente estudo, os alunos reconheceram o fórum de discussão como um espaço para o desenvolvimento de novas aprendizagens facilitadas pelas interações. Nas relações interpessoais, envolvendo questões subjetivas da história de vida, dos valores e da cosmovisão, os participantes se afetaram mutuamente e visaram construir um consenso através do diálogo. Um aspecto importante na forma de implementação do fórum de discussão, nesta experiência, foi a possibilidade de descentralização da figura do professor e de uma releitura do papel discente induzida pela relação dialógica entre pares. $\mathrm{O}$ conhecimento construído por meio da comunicação dos alunos recoloca o papel do professor como facilitador da aprendizagem, no lugar de provedor de informações. Destacaram-se, da maneira como expressaram os participantes nesta pesquisa, a importância do respeito nas relações interpessoais e da autoconfiança, como aspectos das interações que facilitam o trabalho em grupo.

O processo interativo vivenciado promoveu o aprendizado das relações interpessoais, que envolveram afetividades e identidades. $\mathrm{O}$ respeito às diferenças exigiu uma atitude reguladora, o que não implicou não participar, mas encorajou a expressão das ideias divergentes, estimulando a segurança, a liberdade, o respeito mútuo e a tolerância.

Foi possível constatar que, efetivamente, na aprendizagem colaborativa as interações entre os participantes potencializam a aprendizagem, entendida como processo social, de modo que a construção de conhecimentos deslocou-se da análise do indivíduo isolado para conceber as relações dos sujeitos e seus papéis na sociedade.

O fórum de discussão virtual possibilitou criar um ambiente de aprendizagem flexível e colaborativo adequado à construção de conhecimentos de forma autônoma. A ideia central do pressuposto construtivista, baseada no conceito de aprendizagem significativa, considera que a aprendizagem não pode ser entendida unicamente a partir do que se ensina, mas que também é necessário considerar os processos internos de alunos e professores como sujeitos ativos, que possuem espaços, histórias e tempos próprios. Dai que a maior diversidade de perspectivas, num clima de respeito mútuo, enriquece o processo interativo (RUIZ-MORENO; PITAMIGLIO; FURUSATO, 2008). A categorização de habilidades cognitivas, combinada com a análise de conteúdo das mensagens, pode contribuir no processo de avaliação qualitativa e revelar aspectos sobre a aprendizagem de forma mais ampla que os métodos de avaliação estritamente quantitativa. A análise das mensagens, a partir do referencial teórico utilizado nesta pesquisa, oferece subsídios para acompanhar as interações, norteando o pro- 
Formação didático-pedagógica em saúde: ...

cesso de avaliação no ambiente virtual. Em concordância com Van Der Linden, Piconez e Andre (2007), este processo extrapola o modelo tradicional de avaliação, focado na frequência de participação ou na apresentação de trabalhos numa perspectiva exclusivamente individual, seguindo padrões lineares preestabelecidos.

\section{Referências}

ALMEIDA FILHO, N. Universidade nova: textos críticos e esperançosos. Brasília: EDUFBA, 2007.

BATISTA, N. A. et al. A disciplina Formação didático-pedagógica em saúde na pós-graduação stricto sensu da Unifesp/EPM: uma proposta em foco. In: BATISTA, N. A.; BATISTA, S. H. (Org.). Docência em saúde: temas e experiências. São Paulo: Senac, 2004. p. 203-212.

BLIKSTEIN, P.; ZUFFO, M. K. As sereias do ensino eletrônico. In: SILVA, M. (Org.). Educação on-line: teorias, práticas, legislação e formação corporativa. São Paulo: Loyola, 2003. p. 25-40.

BRASIL. Ministério da Educação. Diretrizes curriculares: cursos de graduação. Brasilia, 2001. Disponível em: <http://portal.mec.gov.br/index.php?option=com_content\&view= article\&id=12991>. Acesso em: 29 jul. 2012.

Ministério da Educação. Portaria n ${ }^{\circ}$ 4.059, de 10 de dezembro de 2004. Diário

Oficial da União, Brasília, DF, 13 dez. 2004. Seção 1, p. 34.

Ministério da Educação. Conselho Nacional de Educação. Câmara de Educação

Superior. Resolução CNE/CES n ${ }^{\circ}$ 4, de 07 de novembro de 2001. Institui diretrizes curriculares nacionais do curso de graduação em medicina. Diário Oficial da União, Brasília, DF, 09 nov. 2001. Seção 1. p. 38.

DOLMANS, D. H. J. M. et al. Problem-based learning: future challenges for educational practice and research. Medical Education, Oxford, v. 39, n. 7, p. 732-741, 2005.

FËDOROV, A. N. Siglo XXI, la universidad, el pensamiento crítico y el foro virtual. Revista Ibero-Americana de Educación, La Rioja, v. 38, n. 5, p. 1-10, 2006. Disponível em: <http://www.rieoei.org/1218.htm >. Acesso em: 29 jul. 2012.

FRANCO, M. L. P. B. Análise de conteúdo. 2. ed. Brasília: Liber, 2007.

FREITAS, M. T. A. (Org.). Cibercultura e formação de professores. Belo Horizonte: Autêntica, 2009

FREITAS, M. A.; SEIFERT, O. M. L. B. Formação docente e o ensino de pós-graduação em saúde: uma experiência na Unifesp. Revista Brasileira de Enfermagem, Brasília, DF, v. 60 , n. 6 , p. $635-640,2007$.

GADOTTI, M. Desafios para a era do conhecimento. Revista Viver Mente \& Cérebro, São Paulo, v. 6, p. 5-15, 2006. 
Ruiz-Moreno, L.; Leite, M. T. M.; Ajzen, C.

GOSCIOLA, V. Roteiro para as novas mídias: do game à TV interativa. São Paulo: Senac, 2003.

HARASIM, L. S. R.; TELES, H. L.; TUROFF, M. Redes de aprendizagem: um guia para ensino e aprendizagem on-line. São Paulo: Senac, 2005.

HMELO-SILVER, C. E. Problem-based learning: what and how do students learn. Educational Psychology Review, New York, v. 16, n. 3, p. 235-266, 2004.

HOLEN, A. The PBL group: self-reflections and feedback for improved learning and growth. Medical Teacher, Oxford, v. 22, n. 5, p. 485-488, 2000.

INSTITUTO BRASILEIRO DE GEOGRAFIA E ESTATÍSTICA. Acesso à internet $\mathbf{e}$ posse de telefone móvel celular para uso pessoal 2005. Rio de Janeiro, 2007. Disponível em: <http://www.ibge.gov.br/home/estatistica/populacao/acessoainternet/default.shtm>. Acesso em: 07 maio 2008.

KENSKI, V. M. O ensino e os recursos didáticos em uma sociedade cheia de tecnologias. In: VEIGA, I. P. A. (Org.). Didática: o ensino e suas relações. 6. ed. Campinas: Papirus, 2001. p.127-147.

Tecnologias e ensino presencial e a distância. Campinas: Papirus, 2003.

LEITE, M. T. M. Cursos em educação médica continuada on-line na América Latina: um olhar pedagógico. 2007. 247f . Dissertação (Mestrado em Educação) - Universidade Federal de São Paulo, São Paulo, 2007.

MAIA, C. E.; MATTAR, J. ABC da EaD. São Paulo: Pearson Prentice Hall, 2007.

MINAYO, M. C. S. O desafio do conhecimento: pesquisa qualitativa em saúde. São Paulo: Hucitec: Abrasco, 2004.

MIZUKAMI, M. G. N. Ensino: as abordagens do processo. São Paulo: EPU, 1986.

MORAN, J. M. Contribuições para uma pedagogia on-line. In: SILVA, M. (Org.). Educação on-line: teorias, práticas, legislação e formação corporativa. São Paulo: Loyola, 2003. p. 4152 .

MOREIRA, M.; COSTA, J. W.; OLIVEIRA, C. C. Ambientes informatizados de aprendizagem. Campinas: Papirus, 2001.

OLIVEIRA, M. K. Vygotsky: aprendizado e desenvolvimento, um processo sóciohistórico, São Paulo: Scipione, 1993.

PALLOF, M. R.; PRATT, K. Construindo comunidades de aprendizagem no ciberespaço: estratégias eficientes para salas de aula on-line. Porto Alegre: Artmed, 2002.

PINO, A. As marcas do humano. São Paulo: Cortez, 2005.

RUIZ-MORENO, L.; PITAMIGLIO, S. E. L.; FURUSATO, O. M. A. Lista de discussão como estratégia de ensino-aprendizagem na pós-graduação em saúde. Interface, Botucatu, v. 12, n. 27, p. $883-892,2008$. 
Formação didático-pedagógica em saúde: ...

VAN DER LINDEN, M. M. G.; PICONEZ, S. C. B.; ANDRE, C. F. O uso do fórum num espaço híbrido de aprendizagem: reflexões sobre os processos de avaliação e acompanhamento da interação em fórum on line. In: CONGRESSO INTERNACIONAL DE EDUCAÇÃO A DISTÂNCIA, 13., 2007, Curitiba. Anais... Curitiba: ABED, 2007.

VISSCHERS-PLEIJERS, A. J. S. F. et al. Exploration of a method to analyze group interactions in problem-based learning. Medical Teacher, Oxford, v. 26, n. 5, p. 471-478, 2004.

VYGOTSKY, L. S. Pensamento e linguagem. São Paulo: Martins Fontes, 1995.

A formação social da mente. 6. ed. São Paulo: Martins Fontes, 1998.

Artigo recebido em 15/10/12. Aceito em 16/01/13. 